Table 2. Overview of TEAEs to Week 48 (Safety Set; $N=303$ )

\begin{tabular}{lccc}
\hline $\mathrm{n}(\%)$ & $\begin{array}{c}\text { BKZ 160 mg } \\
(\mathrm{n}=149)\end{array}$ & $\begin{array}{c}\text { BKZ 320 mg } \\
(\mathrm{n}=150)\end{array}$ & $\begin{array}{c}\text { All BKZ [a] } \\
(\mathrm{N}=303)\end{array}$ \\
\hline Any TEAE & $103(69.1)$ & $122(81.3)$ & $235(77.6)$ \\
Drug-related TEAEs & $48(32.2)$ & $54(36.0)$ & $110(36.3)$ \\
Serious TEAEs & $5(3.4)$ & $6(4.0)$ & $13(4.3)$ \\
Discontinuations due to TEAEs & $7(4.7)$ & $10(6.7)$ & $20(6.6)$ \\
\hline
\end{tabular}

[a] Includes TEAEs for 16 and $64 \mathrm{mg} \mathrm{BKZ}$

Disclosure of Interests: Désirée van der Heijde Consultant of: AbbVie, Amgen, Astellas, AstraZeneca, BMS, Boehringer Ingelheim, Celgene, Cyxone, Daiichi, Eisai, Eli-Lilly, Galapagos, Gilead Sciences, Inc., Glaxo-Smith-Kline, Janssen, Merck, Novartis, Pfizer, Regeneron, Roche, Sanofi, Takeda, UCB Pharma; Director of Imaging Rheumatology BV, Lianne S. Gensler Grant/research support from: Pfizer, Novartis, UCB, Consultant of: AbbVie, Eli Lilly, GSK, Novartis, UCB, Atul Deodhar Grant/research support from: AbbVie, Eli Lilly, GSK, Novartis, Pfizer, UCB, Consultant of: AbbVie, Amgen, Boehringer Ingelheim, Bristol Myer Squibb (BMS), Eli Lilly, GSK, Janssen, Novartis, Pfizer, UCB, Speakers bureau: AbbVie, Amgen, Boehringer Ingelheim, Bristol Myer Squibb (BMS), Eli Lilly, GSK, Janssen, Novartis, Pfizer, UCB, Xenofon Baraliakos Grant/research support from: Grant/research support from: AbbVie, BMS, Celgene, Chugai, Merck, Novartis, Pfizer, UCB and Werfen, Consultant of: AbbVie, BMS, Celgene, Chugai, Merck, Novartis, Pfizer, UCB and Werfen, Speakers bureau: AbbVie, BMS, Celgene, Chugai, Merck, Novartis, Pfizer, UCB and Werfen, Denis Poddubnyy Grant/research support from: AbbVie, MSD, Novartis, and Pfizer, Consultant of: AbbVie, Bristol-Myers Squibb, Eli Lilly, MSD, Novartis, Pfizer, Roche, UCB, Speakers bureau: AbbVie, Bristol-Myers Squibb, Eli Lilly, MSD, Novartis, Pfizer, Roche, UCB, Alan Kivitz Shareholder of: AbbVie, Amgen, Gilead, GSK, Pfizer Inc, Sanofi, Consultant of: AbbVie, Boehringer Ingelheim, Flexion, Genzyme, Gilead, Janssen, Novartis, Pfizer Inc, Regeneron, Sanofi, SUN Pharma Advanced Research, UCB, Paid instructor for: Celgene, Genzyme, Horizon, Merck, Novartis, Pfizer, Regeneron, Sanofi, Speakers bureau: AbbVie, Celgene, Flexion, Genzyme, Horizon, Merck, Novartis, Pfizer Inc, Regeneron, Sanofi, Mary Katherine Farmer Employee of: UCB Pharma, Dominique Baeten Employee of: UCB Pharma, Nadine Goldammer Employee of: UCB Pharma, Jason Coarse Employee of: UCB Pharma, Marga Oortgiesen Employee of: UCB Pharma, Maxime Dougados Grant/research support from: AbbVie, Eli Lilly, Merck, Novartis, Pfizer and UCB Pharma, Consultant of: AbbVie, Eli Lilly, Merck, Novartis, Pfizer and UCB Pharma, Speakers bureau: AbbVie, Eli Lilly, Merck, Novartis, Pfizer and UCB Pharma

DOI: 10.1136/annrheumdis-2020-eular.323

\section{OP0106 \\ SECUKINUMAB 150 MG SIGNIFICANTLY IMPROVED SIGNS AND SYMPTOMS OF NON-RADIOGRAPHIC AXIAL SPONDYLOARTHRITIS: 52-WEEK RESULTS FROM THE PHASE III PREVENT STUDY}

J. Braun ${ }^{1}$, R. Blanco ${ }^{2}$, E. Dokoupilova ${ }^{3}$, L. S. Gensler ${ }^{4}$, A. Kivitz ${ }^{5}$, S. Hall ${ }^{6}$, H. Kameda ${ }^{7}$, D. Poddubnyy ${ }^{8}$, M. Van de Sande ${ }^{9}$, D. Van der Heijde ${ }^{10}$, A. Wiksten ${ }^{11}$, B. Porter ${ }^{12}$, H. Richards ${ }^{11}$, S. Haemmerle ${ }^{11}$, A. Deodhar ${ }^{13} .{ }^{1}$ Ruhr Univ. Bochum, Bochum, Germany; ${ }^{2}$ Hospital Univ. Marqués de Valdecilla, Santander, Spain; ${ }^{3}$ MEDICAL PLUS s.r.o., Univ. of Veterinary \& Pharma. Sciences, Brno, Czech Republic; ${ }^{4}$ Univ. of California, San Francisco, San Francisco, United States of America; ${ }^{5}$ Altoona Center for Clinical Research, Duncansville, United States of America; ${ }^{6}$ Monash Univ., Melbourne, Australia; ${ }^{7}$ Toho Univ., Tokyo, Japan; ${ }^{8}$ Charité Universitätsmedizin Berlin, Berlin, Germany; ${ }^{9}$ Rheumatology \& Immunology Center, Amsterdam, Netherlands; ${ }^{10}$ Univ. Medical Centre, Leiden, Netherlands; ${ }^{11}$ Novartis Pharma AG, Basel, Switzerland; ${ }^{12}$ Novartis Pharma. Corp., East Hanover, United States of America; ${ }^{13}$ Oregon Health \& Science Univ., Portland, United States of America

Background: Axial spondyloarthritis (axSpA) spectrum covers radiographic axSpA and non-radiographic axSpA (nr-axSpA). PREVENT (NCT02696031) is the first phase III, placebo (PBO) controlled study evaluating secukinumab (SEC) $150 \mathrm{mg}$ with (LD) or without loading (NL) dose, in patients (pts) with nr-axSpA. ${ }^{1}$ The study had 2 independent analysis plans as per EU (Wk 16) and US (Wk 52) regulatory requirements.

Objectives: To report efficacy through Wk 52 and safety up to two years for the PREVENT study.

Methods: 555 pts fulfilling ASAS criteria for axSpA plus abnormal CRP and/or $\mathrm{MRI}$, without evidence of radiographic changes in sacroiliac (SI) joints according to modified New York Criteria for AS were enrolled. All images were assessed centrally before inclusion. Pts were randomised $(1: 1: 1)$ to SEC $150 \mathrm{mg}$ with LD, $\mathrm{NL}$, or PBO at baseline (BL). LD pts received SEC $150 \mathrm{mg}$ at Wks 1, 2, 3, and 4 , and then every 4 wks (q4wk) starting at Wk 4. NL pts received SEC $150 \mathrm{mg}$ at $\mathrm{BL}$ and PBO at Wks 1, 2, and 3, and then $150 \mathrm{mg}$ q4wk. Switch to open-label
(OL) SEC $150 \mathrm{mg}$ or standard of care (SoC) was permitted after Wk 20. Primary endpoint was ASAS40 at Wk 16 (LD) and at Wk 52 (NL) in anti-TNF-naïve pts. Secondary endpoints (overall population) included ASAS40, BASDAI50, SI joint bone marrow edema (BME) score by MRI at Wks 16 and 52 and ASDAS-CRP inactive disease (ID) at Wk 52. Endpoints were analysed according to statistical hierarchy. Analysis used non responder imputation through Wk 52 . Safety analyses included all pts who received $\geq 1$ dose of study treatment.

Results: Overall, 481 pts completed 52 wks with no major differences in retention across groups: 84.3\% (156/185; LD), 89.7\% (165/184; NL) and 86.0\% (160/186; PBO). BL characteristics were similar across groups; $90 \%$ pts were anti-TNFnaïve, $56-58 \%$ pts had elevated CRP, $71-75 \%$ pts had evidence of SI joint inflammation by MRI. Proportion of pts who switched to OL or SoC between Wks 20 and 48 was $52.1 \%$ (LD), $49.2 \%$ (NL), and $67.4 \%$ (PBO). Primary endpoints at Wk 16 and Wk 52 were met (Table). SEC $150 \mathrm{mg}$ LD or NL significantly improved secondary endpoints at Wk 16 and 52 vs $\mathrm{PBO}$ (Table). SEC significantly reduced SI joint MRI BME score vs PBO at WK $16(-1.68$ and -1.03 vs $-0.39 ; P=0.0197$ and 0.026 , LD and NL respectively). No unexpected safety signals were reported. Conclusion: SEC $150 \mathrm{mg}$ provided significant and sustained improvement in signs and symptoms of pts with nr-axSpA through Wk 52. MRI BME scores were reduced accordingly. There was no major difference between LD and NL. Safety of SEC was consistent with previous reports. ${ }^{2}$

References:

[1] Deodhar A, et al. Arthritis Rheumatol. 2019;71(suppl 10).

[2] Deodhar A, et al. Arth Res Ther. 2019;21:111.

\section{Table}

\begin{tabular}{lcccc}
\hline Endpoints, \% responders & Wk & $\begin{array}{c}\text { SEC } \\
150 \mathrm{mg} \text { LD } \\
(\mathrm{N}=185)\end{array}$ & $\begin{array}{c}\text { SEC } \\
150 \mathrm{mg} \mathrm{NL} \\
(\mathrm{N}=184)\end{array}$ & $\begin{array}{c}\text { PBO } \\
(\mathrm{N}=186)\end{array}$ \\
\hline Primary & & & & \\
ASAS40 in anti-TNF-naïve pts & 16 & $41.5^{\ddagger}$ & $42.2^{\ddagger}$ & 29.2 \\
& 52 & $35.4^{\ddagger}$ & $39.8^{\ddagger}$ & 19.9 \\
Secondary & 16 & $40.0^{\ddagger}$ & $40.8^{\ddagger}$ & 28.0 \\
ASAS40 & 52 & $33.5^{\ddagger}$ & $38.0^{\ddagger}$ & 19.4 \\
BASDAI50 & 16 & $37.3^{\ddagger}$ & $37.5^{\ddagger}$ & 21.0 \\
& 52 & $30.8^{\ddagger}$ & $35.3^{\ddagger}$ & 19.9 \\
ASDAS-CRP ID & 16 & $20.5^{\dagger}$ & $21.7^{\dagger}$ & 8.1 \\
& 52 & 15.7 & $23.9^{\ddagger}$ & 10.2
\end{tabular}

${ }^{\dagger} P<0.001 ;{ }^{\ddagger} P<0.05$ vs PBO ( $P$ values are adjusted for multiplicity of testing at Wks 16 and 52. Unadjusted $P$ value for ASDAS-CRP ID at Wk 16). Missing values were imputed as non-response.

$\mathrm{N}$, number of randomised pts

Disclosure of Interests: Juergen Braun Grant/research support from: Abbvie (Abbott), Amgen, BMS, Boehringer, Celgene, Celltrion, Centocor, Chugai, El Lilly and Company, Medac, MSD (Schering Plough), Mundipharma, Novartis, Pfizer (Wyeth), Roche, Sanofi- Aventis, and UCB Pharma, Consultant of: Abbvie (Abbott), Amgen, BMS, Boehringer, Celgene, Celltrion, Centocor, Chugai, EBEWE Pharma, Eli Lilly and Company, Medac, MSD (Schering-Plough), Mundipharma, Novartis, Pfizer (Wyeth), Roche, Sanofi-Aventis, and UCB Pharma, Speakers bureau: Abbvie (Abbott), Amgen, BMS, Boehringer, Celgene, Celltrion, Centocor, Chugai, EBEWE Pharma, Eli Lilly and Company, Medac, MSD (Schering-Plough), Mundipharma, Novartis, Pfizer (Wyeth), Roche, SanofiAventis, and UCB Pharma, Ricardo Blanco Grant/research support from: AbbVie, MSD, Roche, Consultant of: Abbvie, Eli Lilly, Pfizer, Roche, Bristol-Myers, Janssen, UCB Pharma and MSD, Speakers bureau: Abbvie, Eli Lilly, Pfizer Roche, Bristol-Myers, Janssen, UCB Pharma. MSD, Eva Dokoupilova Grant/ research support from: Eli Lilly, AbbVie, Novartis, Lianne S. Gensler Grant/ research support from: Pfizer, Novartis, UCB, Consultant of: AbbVie, Eli Lilly, GSK, Novartis, UCB, Alan Kivitz Shareholder of: AbbVie, Amgen, Gilead, GSK, Pfizer Inc, Sanofi, Consultant of: AbbVie, Boehringer Ingelheim, Flexion, Genzyme, Gilead, Janssen, Novartis, Pfizer Inc, Regeneron, Sanofi, SUN Pharma Advanced Research, UCB, Paid instructor for: Celgene, Genzyme, Horizon, Merck, Novartis, Pfizer, Regeneron, Sanofi, Speakers bureau: AbbVie, Celgene, Flexion, Genzyme, Horizon, Merck, Novartis, Pfizer Inc, Regeneron, Sanofi, Stephen Hall Grant/research support from: Abbvie, UCB, Janssen, Merck, Hideto Kameda Grant/research support from: Abbvie, Asahi-Kasei, Chugai, Eisai, Mitsubishi-Tanabe and Novartis, Consultant of: Abbvie, Boehringer, Celgene, Eli Lilly, Janssen, Novartis, Sanofi, UCB, Speakers bureau: Abbvie, Asahi-Kasei, BMS, Chugai, Eisai, Eli Lilly, Janssen, Mitsubishi-Tanabe, Novartis and Pfizer, Denis Poddubnyy Grant/research support from: AbbVie, MSD, Novartis, and Pfizer, Consultant of: AbbVie, Bristol-Myers Squibb, Eli Lilly, MSD, Novartis, Pfizer, Roche, UCB, Speakers bureau: AbbVie, Bristol-Myers Squibb, Eli Lilly, MSD, Novartis, Pfizer, Roche, UCB, Marleen van de Sande Grant/research support from: Novartis, Eli Lilly, Boehringer Ingelheim, Janssen, Consultant of: Abbvie, Novartis, Eli Lilly, Speakers bureau: Novartis, MSD, Désirée van der Heijde 
Consultant of: AbbVie, Amgen, Astellas, AstraZeneca, BMS, Boehringer Ingelheim, Celgene, Cyxone, Daiichi, Eisai, Eli-Lilly, Galapagos, Gilead Sciences, Inc., Glaxo-Smith-Kline, Janssen, Merck, Novartis, Pfizer, Regeneron, Roche, Sanofi, Takeda, UCB Pharma; Director of Imaging Rheumatology BV, Anna Wiksten Shareholder of: Novartis, Employee of: Novartis, Brian Porter Shareholder of: Novartis, Employee of: Novartis, Hanno Richards Shareholder of: Novartis, Employee of: Novartis, Sibylle Haemmerle Shareholder of: Novartis, Employee of: Novartis, Atul Deodhar Grant/research support from: AbbVie, Eli Lilly, GSK, Novartis, Pfizer, UCB, Consultant of: AbbVie, Amgen, Boehringer Ingelheim, Bristol Myer Squibb (BMS), Eli Lilly, GSK, Janssen, Novartis, Pfizer, UCB, Speakers bureau: AbbVie, Amgen, Boehringer Ingelheim, Bristol Myer Squibb (BMS), Eli Lilly, GSK, Janssen, Novartis, Pfizer, UCB DOI: 10.1136/annrheumdis-2020-eular.598

\section{OP0107 ETANERCEPT WITHDRAWAL AND RE-TREATMENT IN PATIENTS WITH INACTIVE NON-RADIOGRAPHIC AXIAL SPONDYLOARTHRITIS AT 24 WEEKS: RESULTS OF RE-EMBARK, AN OPEN-LABEL, PHASE IV TRIAL}

F. Van den Bosch ${ }^{1}$, J. C. C. Wei ${ }^{2}$, P. $\mathrm{Nash}^{3}$, F. J. Blanco ${ }^{4}$, D. Graham ${ }^{5}$, C. Zang ${ }^{5}$, E. Arthur ${ }^{6}$, C. Borlenghi ${ }^{7}$, B. Vlahos ${ }^{5}$, A. Deodhar ${ }^{8} .{ }^{1}$ Ghent University Hospital, Gent, Belgium; ${ }^{2}$ Chung Shan Medical University Hospital, Taichung, Taiwan, Republic of China; ${ }^{3}$ Griffith University, Brisbane, Australia; ${ }^{4}$ INIBIC-Hospital Universitario A Coruña, La Coruña, Spain; ${ }^{5}$ Pfizer, Collegeville, United States of America; ${ }^{6}$ Pfizer, New York, United States of America; ${ }^{7}$ Pfizer, Buenos Aires, Argentina; ${ }^{8}$ Oregon Health \& Science University, Portland, United States of America

Background: In the RE-EMBARK trial (NCT02509026), etanercept (ETN)treated patients with non-radiographic axial spondyloarthritis (nr-axSpA) who achieved inactive disease (defined as Ankylosing Spondylitis Disease Activity Score with C-reactive protein $[$ ASDAS CRP] $<1.3)$ in Period $1(\mathrm{P} 1)^{1}$ discontinued ETN for $\leq 40$ weeks.

Objectives: To assess the proportion of patients with inactive disease after P1 who experienced disease flare (ASDAS with erythrocyte sedimentation rate [ASDAS ESR] $\geq 2.1$ ) within 40 weeks of ETN withdrawal and to estimate time to flare following ETN withdrawal.

Methods: RE-EMBARK was a multicenter, open-label, Phase IV trial of ETN in patients with active nr-axSpA (meeting Assessment in SpondyloArthritis international Society criteria and with ASDAS CRP $\geq 2.1$ ) and an inadequate response to $\geq 2$ nonsteroidal anti-inflammatory drugs (NSAIDs) while taking a stable dose of 1 NSAID for $\geq 2$ weeks before the first ETN dose. All patients received ETN (50 mg/ week) plus NSAID for the first 24 weeks (P1). At week 24, patients with inactive disease discontinued ETN for $\leq 40$ weeks (Period 2 [P2]). Those who experienced flare during P2 were re-treated with ETN for 12 weeks in Period 3 (P3). Kaplan-Meier (KM) analysis and Cox proportional hazard models were used to 1) estimate the probability of experiencing flare within a given time period, and 2) compare data between RE-EMBARK and the EMBARK trial (NCT01258738) of patients with nr-axSpA who met RE-EMBARK P2 entry criteria (achieved inactive disease after 24 weeks of ETN treatment) and continued treatment for a further $\leq 40$ weeks.

Results: Of the 209 patients in P1 (mean age, 33 years; women, 46\%; white, $89 \%), 119(57 \%)$ entered P2. The proportion of patients experiencing $\geq 1$ flare increased from 22\% (25/112) at P2 week 4 to $67 \%(77 / 115)$ at P2 week 40. Overall, $75 \%$ (86/115) of patients in P2 experienced flare and 50\% experienced flare within 16 weeks (95\% Cl: 13-24 weeks, KM analysis). Conversely, data from the comparator EMBARK trial suggested that $<25 \%$ of patients receiving continuous ETN treatment over 40 weeks experienced flare. Cox proportional hazard model analysis showed an $85 \%$ relative risk reduction of experiencing flare during P2 in patients with inactive disease who continued ETN treatment vs those who discontinued. By P3 end 62\% (54/87) of patients re-treated with ETN re-achieved inactive disease; $50 \%$ of patients who re-achieved inactive disease in P3 did so within 5 weeks (95\% Cl: 4-8 weeks, KM analysis). The observed trend of clinical improvement (P1), worsening (P2), and improvement (P3) was reflected in other clinical measures (Figure) plus measures of joint damage (Spondyloarthritis Research Consortium of Canada Sacroiliac Joint magnetic resonance imaging score) and quality of life (EQ-5D visual analog scale score); mean (standard deviation) score changes from each study period baseline-end were -6.1 (11.7) [P1], +1.5 (4.4) [P2], -2.0 (8.8) [P3] and +27.7 (26.7) [P1], -26.4 (30.5) [P2], +32.1 (26.3) [P3], respectively. There were no unexpected safety signals.

Conclusion: For patients with nr-axSpA who achieved inactive disease with ETN and then discontinued treatment, a quarter maintained treatment-free inactive disease for 40 weeks and $50 \%$ maintained an ASDAS ESR score of $<2.1$ for $\geq 16$ weeks. Re-starting ETN allowed $62 \%$ of patients who flared to re-achieve inactive disease within 12 weeks.
References:

[1] Van den Bosch F, et al. Ann Rheum Dis 2019;78:896-7

Figure: Clinical Assessments by RE-EMBARK Study Period

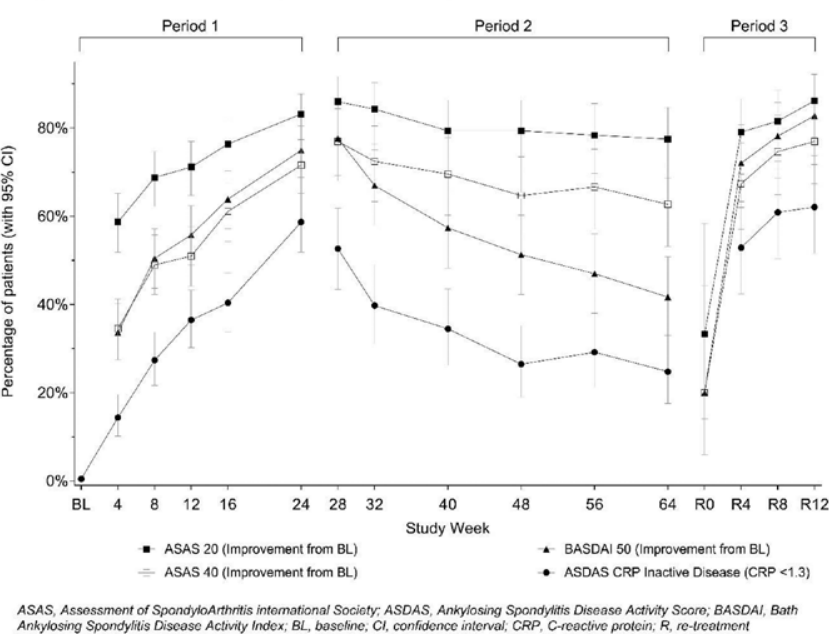

Acknowledgments: Medical writing support was provided by Lorna Forse, $\mathrm{PhD}$, of Engage Scientific Solutions and was funded by Pfizer.

Disclosure of Interests: Filip van den Bosch Consultant of: AbbVie, Celgene Corporation, Eli Lilly, Galapagos, Janssen, Novartis, Pfizer, and UCB, Speakers bureau: AbbVie, Celgene Corporation, Eli Lilly, Galapagos, Janssen, Novartis Pfizer, and UCB, James Cheng-Chung Wei Grant/research support from: AbbVie, Bristol-Myers Squibb, Celgene, Eli Lilly, Janssen, Novartis, Pfizer Inc, UCB Consultant of: AbbVie, Bristol-Myers Squibb, Celgene, Chugai, Eisai, Janssen, Novartis, Pfizer Inc, Sanofi-Aventis, UCB Pharma, Peter Nash Grant/research support from: AbbVie, Bristol-Myers Squibb, Celgene, Eli Lilly and Company Gilead, Janssen, MSD, Novartis, Pfizer Inc, Roche, Sanofi, UCB, Consultant of: AbbVie, Bristol-Myers Squibb, Celgene, Eli Lilly, Gilead, Janssen, MSD, Novartis, Pfizer Inc, Roche, Sanofi, UCB, Speakers bureau: AbbVie, Bristol-Myers Squibb, Celgene, Eli Lilly, Gilead, Janssen, MSD, Novartis, Pfizer Inc, Roche, Sanofi, UCB, Francisco J. Blanco Grant/research support from: Sanofi-Aventis Lilly, Bristol MS, Amgen, Pfizer, Abbvie, TRB Chemedica International, Glaxo SmithKline, Archigen Biotech Limited, Novartis, Nichi-iko pharmaceutical Co Genentech, Jannsen Research \& Development, UCB Biopharma, Centrexion Theurapeutics, Celgene, Roche, Regeneron Pharmaceuticals Inc, Biohope, Corbus Pharmaceutical, Tedec Meiji Pharma, Kiniksa Pharmaceuticals, Ltd Gilead Sciences Inc, Consultant of: Lilly, Bristol MS, Pfizer, Daniela Graham Shareholder of: Pfizer Inc, Employee of: Pfizer Inc, Chuanbo Zang Shareholde of: Pfizer, Employee of: Pfizer, Edmund Arthur Shareholder of: Pfizer, Employee of: Pfizer, Cecilia Borlenghi Shareholder of: Pfizer, Employee of: Pfizer, Bonnie Vlahos Shareholder of: Pfizer, Employee of: Pfizer, Atul Deodhar Grant/ research support from: AbbVie, Eli Lilly, GSK, Novartis, Pfizer, UCB, Consultant of: AbbVie, Amgen, Boehringer Ingelheim, Bristol Myer Squibb (BMS), El Lilly, GSK, Janssen, Novartis, Pfizer, UCB, Speakers bureau: AbbVie, Amgen, Boehringer Ingelheim, Bristol Myer Squibb (BMS), Eli Lilly, GSK, Janssen, Novartis, Pfizer, UCB

DOI: 10.1136/annrheumdis-2020-eular.1322

\section{OP0108 \\ RANDOMIZED CONTROLLED TRIAL OF ORAL CORTICOSTEROIDS IN AXIAL SPONDYLOARTHROPATHY: MODIFIED COBRA REGIME}

D. Mishra ${ }^{1}$, G. Naidu ${ }^{1}$, V. Kumar ${ }^{1}$, S. K. Sharma ${ }^{1}$, A. Sharma ${ }^{1}$, S. Jain ${ }^{1}$, V. Dhir ${ }^{1}$. ${ }^{1}$ Postgraduate Institute of Medical Education and Research, Chandigarh, India

Background: There is an unmet need of anti-inflammatory agents in AxSpA after NSAID failure. This is especially true for patients with persisting high dis ease activity and not having access to anti-TNFa. In this regard, corticosteroids may be helpful as a short-term measure. However, current guidelines recommend against oral corticosteroids citing insufficient evidence of efficacy. ${ }^{1}$. Also, there is an assumption that the dose required for benefit is much higher than RA and thus untenable. It is unclear whether starting with a high dose followed by rapid taper would be effective (like the COBRA regime in $R A)^{2}$.

Objectives: To study the efficacy of the COBRA regime of oral corticosteroids in axial SpA over 24 weeks.

Methods: This was a double blind placebo controlled randomized trial. Patients with active axial SpA (BASDAI $\geq 4$ ) despite NSAIDs were randomized to either 